\title{
8. Protecting Traditional KnOWLedge in Australia: What CAN WE LEARN From
} INDIA AND PERU?

\section{EVANA WRIGHT*}

Indigenous people and local communities hold, maintain and develop knowledge, innovations and practices that are derived from complex, dynamic knowledge systems intricately linked to culture and place. ${ }^{1}$ This 'traditional knowledge' has application in fields such as agriculture, horticulture, fisheries and health ${ }^{2}$ and is of cultural, spiritual and economic value to Indigenous and local communities. ${ }^{3}$ This value has led to the exploitation and misappropriation of traditional knowledge without the prior informed consent of the Indigenous community that holds the knowledge or the sharing of benefits arising out of its use. The acts of biopiracy have often involved the erroneous grant of patents over traditional knowledge and in response, attempts have been made at an international level to develop and implement mechanisms for the protection of traditional knowledge.

The Convention on Biological Diversity ('CBD') ${ }^{4}$ provides a framework for the protection of biological resources and associated traditional knowledge utilising an access and benefit sharing regime operating on the principles of prior informed consent or the approval and involvement of Indigenous communities and the equitable sharing of benefits. ${ }^{5}$ These principles have been implemented through the Nagoya Protocol on Access to Genetic Resources and the Fair and Equitable Sharing of Benefits Arising from their Utilisation to the Convention on Biological Diversity ('Nagoya Protocol') which entered into force in October

\footnotetext{
- All online sources were last accessed on 10 July 2018.

${ }^{1}$ CBD Secretariat, 'Development of Elements of Sui Generis Systems for the Protection of Traditional Knowledge, Innovations and Practices to Identify Priority Elements' (20 September 2007) UNEP/CBD/WG8J/5/6, 16; Peter Drahos and Susy Frankel, 'Indigenous Peoples' Innovation and Intellectual Property: The Issues' in Peter Drahos and Susy Frankel (eds), Indigenous Peoples' Innovation: Intellectual Property Pathways to Development (ANU E Press 2012) 1, 13.

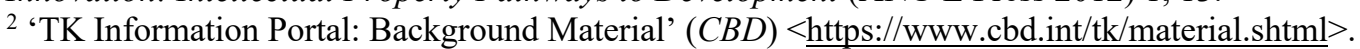

${ }^{3}$ Susette Biber-Klemm and Danuta Szymura Berglas, 'Problems and Goals' in Susette Biber-Klemm, Thomas Cottier and Danuta Szymura Berglas (eds), Rights to Plant Genetic Resources and Traditional Knowledge: Basic Issues and Perspectives (CAB International on behalf of the Swiss Agency for Development and Cooperation and the World Trade Institute 2006) 3, 21; Graham Dutfield, Developing and Implementing National Systems for Protecting Traditional Knowledge: A Review of Experiences in Selected Developing Countries (UNCTAD Expert Meeting on Systems and National Experiences for Protecting Traditional Knowledge, Innovations and Practices 2000) 7; Krishna Ravi Srinivas, 'Traditional Knowledge and Intellectual Property Rights: A Note on Issues, Some Solutions and Some Suggestions' (2008) 3 Asian Journal WTO and International Health Law and Policy 81, 86.

${ }^{4}$ Convention on Biological Diversity (opened for signature 5 June 1992, entered into force 29 December 1993) 1760 UNTS 30619 (hereafter CBD).

${ }^{5}$ Ibid arts $8(\mathrm{j}), 15,19$.
} 
2014. ${ }^{6}$ Australia is a signatory to the Nagoya Protocol $^{7}$ and as such is required to implement measures ensuring access to genetic resources and traditional knowledge is subject to prior informed consent or approval and involvement of Indigenous communities and upon mutually agreed terms, ${ }^{8}$ thus providing an opportunity to review and evaluate the mechanisms governing the protection of traditional knowledge in Australia. As part of this process there is value in studying the approach taken in other jurisdictions and identifying key lessons for Australia in the design and implementation of a nationally consistent regime for the protection of traditional knowledge. ${ }^{9}$

This chapter will commence with a critical review of the current protection of traditional knowledge in Australia and identify gaps in protection that may be used to facilitate the continuing misappropriation and exploitation of traditional knowledge. Following the review is a comparative analysis of the regimes of India and Peru for the protection of traditional knowledge with a focus on the use of access and benefit sharing schemes and databases. The objective of the analysis is to identify lessons for Australia in the design and implementation of a nationally consistent regime for the protection of traditional knowledge.

\section{Traditional knowledge and Australia: Current situation}

Australia is one of the world's 17 mega-diverse countries ${ }^{10}$ and is home to approximately $13 \%$ of the world's biodiversity ${ }^{11}$ with many endemic plant and animal species. ${ }^{12}$ There are numerous examples in Australia of traditional knowledge of Aboriginal and Torres Strait Islander people being appropriated and exploited by third parties through acts of biopiracy,

\footnotetext{
${ }^{6}$ Nagoya Protocol on Access to Genetic Resources and the Fair and Equitable Sharing of Benefits Arising from their Utilisation to the Convention on Biological Diversity (opened for signature 2 February 2011, entered into force 12 October 2014).

${ }^{7}$ Australia signed the Nagoya Protocol on 20 January 2012 but is yet to ratify the Protocol.

${ }^{8}$ Nagoya Protocol (n 6) arts 6, 7, 12.

${ }_{9}^{9}$ Natalie Stoianoff, 'Navigating the Landscape of Indigenous Knowledge - A Legal Perspective' (2012) 90 IPF 23; Edward J Eberle, 'The Method and Role of Comparative Law' (2009) 8(3) Wash U Global Stud L Rev 451; Alan Watson, Legal Transplants: An Approach to Comparative Law (Scottish Academic Press 1974).

${ }^{10}$ See Russell A Mittermeier, Patricio Robles Gil and Cristina Goettsch Mittermeier, Megadiversity: Earth's Biologically Wealthiest Nations (Conservation International 1999). Conservation International and the United Nations Environment Program (UNEP) World Conservation Monitoring Centre recognises 17 mega-diverse countries accounting for more than $79 \%$ of the world's biodiversity. The countries classified as mega-diverse are: Australia, Brazil, China, Colombia, the Democratic Republic of the Congo, Ecuador, India, Indonesia, Madagascar, Malaysia, Mexico, Papua New Guinea, Peru, the Philippines, South Africa, the United States of America and Venezuela.

${ }^{11}$ Australian Government, Commonwealth Public Inquiry: Access to Biological Resources in Commonwealth Areas (Canberra, 2000) [1.28].

${ }^{12}$ Geoff Burton, 'Australian ABS Law and Administration - A Model Law and Approach' in Evanson C Kamau and Gerd Winter (eds), Genetic Resources, Traditional Knowledge and the Law (Earthscan 2009) 272.
} 
that is the taking of traditional knowledge without the prior informed consent or involvement of Indigenous and local communities holding such knowledge and without the fair and equitable sharing of benefits arising from such use. ${ }^{13}$ Such acts of bio-piracy in Australia include attempts to patent an extract from Kakadu plum, a plant native to Australia and used by Indigenous Australians for hundreds of years, ${ }^{14}$ and the grant of plant breeder's rights over Australian native plants with known traditional uses. ${ }^{15}$ While some protection is afforded to traditional knowledge in Australia, the existing measures are fragmented across Federal, State and Territory jurisdictions and may be easily circumvented. ${ }^{16}$

The Environment Protection and Biodiversity Conservation Act 1999 (Cth) ('EPBC Act') was implemented in response to Australia's obligations under the CBD with the objective of promoting the conservation and sustainable use of biological resources. ${ }^{17}$ The EPBC Act provides for, inter alia, a regime whereby access to biological resources in Commonwealth areas requires a permit to be issued by the Minister for the Environment. ${ }^{18}$ Section 301 of the EPBC Act states that the 'regulations may provide for the control of access to biological resources in Commonwealth areas'. ${ }^{19}$ Regulation 8A.01 sets out the purpose of the regulations with regards to section 301 of the EPBC Act as providing for:

'... the control of access to biological resources in Commonwealth areas to which this Part applies by:

(a) promoting the conservation of biological resources in those Commonwealth areas including the ecologically sustainable use of those biological resources; and

\footnotetext{
13 'Patents \& Biopiracy' (ETC Group) < www.etcgroup.org/issues/patents-biopiracy>; Graham Dutfield, Developing and Implementing National Systems for Protecting Traditional Knowledge: A Review of Experiences in Selected Developing Countries (UNCTAD Expert Meeting on Systems and National Experiences for Protecting Traditional Knowledge, Innovations and Practices 2000).

${ }^{14}$ Daniel Robinson, Confronting Biopiracy: Challenges, Cases and International Debates (Earthscan 2010) 75; Daniel F Robinson, 'Traditional Knowledge and Biological Product Derivative Patents: Benefit-Sharing and Patent Issues Relating to Camu Camu, Kakadu Plum and Acai Plant Extracts' (April 2010) Traditional Knowledge Bulletin: Tropical Issues Series 1, 5. See also PCT Patent No WO/2007/084998 'Compositions comprising kakadu plum extract or acai berry extract'.

${ }^{15}$ Henrietta Fourmile-Marrie, 'Developing a Regime to Protect Indigenous Traditional BiodiversityRelated Knowledge' (2000) 1 Balayi 163, 166; Rural Advancement Foundation International (RAFI) and Heritage Seed Curators Australia (HSCA), Plant Breeder's Wrongs: An Inquiry into the Potential for Plant Piracy through International Intellectual Property Conventions (1998).

${ }^{16}$ The Commonwealth of Australia is made up of six states (New South Wales, Queensland, Victoria, South Australia, Western Australia and Tasmania) and ten territories. Two of the territories have been granted rights of self-government by the Commonwealth (these are Australian Capital Territory and Northern Territory). References to Territories in this chapter are references to the Australian Capital Territory and the Northern Territory only.

${ }^{17}$ EPBC Act 1999, s 3(1)(b).

${ }^{18}$ Environment Protection and Biodiversity Conservation Regulations 2000 (Cth) ('EPBC Regulations'), reg 8A.06.

${ }^{19}$ Specific provisions relating to access to biological resources and associated traditional knowledge are set out in reg $8 \mathrm{~A}$ of the EPBC Regulations.
} 
(b) ensuring the equitable sharing of benefits arising from the use of biological resources in those Commonwealth areas; and

(c) recognising the special knowledge held by indigenous persons about biological resources; and

(d) establishing an access regime designed to provide certainty, and minimise administrative cost, for people seeking access to biological resources; and

(e) seeking to ensure that the social, economic and environmental benefits arising from the use of biological resources in those Commonwealth areas accrue to Australia; and

(f) contributing to a nationally consistent approach to access to Australia's biological resources.'

This regime distinguishes between access for commercial or potentially commercial activities and access for non-commercial purposes. Where access is for commercial or potentially commercial purposes, the party seeking access must apply for a permit and enter into a benefit-sharing agreement with the access provider. The agreement must cover details such as the purpose of the access, the benefits to be provided in return for access, the use of any traditional knowledge and involvement of Indigenous communities (where relevant). ${ }^{20}$ Where the proposed access involves the use of traditional knowledge, the benefit-sharing arrangements must provide for both the protection and recognition of Indigenous peoples' knowledge. ${ }^{21}$ This includes a statement regarding the source and use of such knowledge, ${ }^{22}$ as well as the benefits to be provided to the relevant Indigenous community in return. ${ }^{23}$ Access for non-commercial purposes is subject to a lower threshold of requirements although a permit must still be obtained. ${ }^{24}$ Where access is for non-commercial purposes, the applicant is required to provide a statutory declaration certifying that they do not intend to use the biological resources for commercial purposes, ${ }^{25}$ and to undertake not to carry out research and development for commercial purposes unless they enter into a benefit-sharing agreement with the access provider. ${ }^{26}$

According to the Australian Government, 275 permits were issued under the EPBC Act during the period October 2006 to December 2015 with only three of these being for

\footnotetext{
${ }^{20}$ Ibid reg 8A.07. The Australian Government through the Department of Environment provides model access and benefit sharing agreements on their website. See Australian Government: Department of the Environment, 'Deed of Agreement in relation to Access to Biological Resources in Commonwealth Areas for Commercial or Potential Commercial Purposes and Benefit-Sharing' $<$ www.environment.gov.au/system/files/pages/e3584028-d083-4aec-acddc0aa635a529f/files/commonwealth-and-access-party-model-benefit-sharing-agreement-2012.pdf $>$. ${ }^{21}$ EPBC Regulations (n 18) reg 8A.08.

${ }^{22}$ Ibid reg 8A.08(h).

${ }^{23}$ Ibid reg 8A.08(i).

${ }^{24}$ Ibid reg 8A.12.

${ }^{25}$ Ibid reg 8A.13(a).

${ }^{26}$ Ibid reg 8A.13(e).
} 
commercial purposes.$^{27}$ It should be noted however, that these figures do not represent the full extent of access to biological resources and associated traditional knowledge in Australia as the EPBC Act only applies to 'Commonwealth areas', as defined in section 525 of the EPBC Act. ${ }^{28}$ Biological resources and associated traditional knowledge are dispersed across Australia and are not limited to 'Commonwealth areas' as defined under the EPBC Act. The operation of the Act is further restricted by the EPBC Regulations which state that the regime 'does not apply to land leased by the Commonwealth or a Commonwealth agency unless the Commonwealth or Commonwealth agency that holds the lease also holds a usage right in relation to the land that entitles the lessee to control access to the biological resources in and on the land. ${ }^{29}$ While it has been estimated that the EPBC Act and Regulations cover approximately $5 \%$ of the world's biodiversity the EPBC Act does not cover jurisdictions outside of 'Commonwealth areas' such as State or private lands. ${ }^{30}$

In addition to the framework established under the EPBC Act, access to biological resources and associated traditional knowledge in Australia is also governed by the terms of various State and Territory legislation and policies. While the States and Territories have endorsed the 'Nationally Consistent Approach for Access to and the Utilisation of Australia's Native Genetic and Biochemical Resources' ${ }^{31}$ and, therefore, committed to the National Strategy for the Conservation of Australia's Biological Diversity, ${ }^{32}$ the protection of traditional knowledge in Australia remains inconsistent and fragmented across each jurisdiction.

The Biological Resources Act 2006 (NT) ('Biological Resources Act') was implemented for the purpose of facilitating bio-prospecting in the Northern Territory, ${ }^{33}$ and explicitly recognises the importance of traditional knowledge associated with biological resources. ${ }^{34}$

\footnotetext{
${ }^{27}$ Australian Government: Department of the Environment, 'List of permits issued'

$<$ www.environment.gov.au/resource/list-permits-issued $>$. It should be noted that these figures exclude any permits granted by the Great Barrier Reef Marine Park Authority, the Australian National Botanic Gardens, the Australian Institute of Marine Sciences and the Australian Antarctic Division. According to a report submitted by the Australian Government to the WIPO IGC, over 400 permits have been issued under Part 8A of the EPBC Regulations and other regimes. See WIPO, Intergovernmental Committee on Intellectual Property and Genetic Resources, Traditional Knowledge and Folklore, Policies, Measures and Experiences Regarding Intellectual Property and Genetic Resources: Submission by Australia (19 February 2010) WIPO/GRTKF/IC/16/INF/18 Annex.

${ }^{28}$ EPBC Act (n 17) s 525(1) defines 'Commonwealth area' and covers land owned or leased by the Commonwealth or a Commonwealth agency, the coastal sea, continental shelf and waters of the exclusive economic zone.

${ }^{29}$ EPBC Regulations (n 18) reg 8A.02.

${ }^{30}$ Burton (n 12) 273.

${ }^{31}$ Natural Resource Management Ministerial Council, Nationally Consistent Approach for Access to and the Utilisation of Australia's Native Genetic and Biochemical Resources (October 2002).

32 Australian Government: Department of Environment, Sport and Territories (Cth), National Strategy for the Conservation of Australia's Biological Diversity (1996).

${ }^{33}$ Biological Resources Act 2006 (NT), s 3(1).

${ }^{34}$ Ibid s 3(2)(d).
} 
The Biological Resources Act provides for an access and benefit-sharing regime and contains specific provisions governing access to biological resources on Aboriginal land, ${ }^{35}$ and the use of traditional knowledge (referred to as 'indigenous person's knowledge' in the Act). ${ }^{36}$ Similar to the process established under the EPBC Act, a permit must be obtained from the relevant authority prior to engaging in bio-prospecting, ${ }^{37}$ and a benefit sharing agreement must be entered into with the access provider. ${ }^{38}$ The benefit sharing agreement must contain statements setting out the use of indigenous people's knowledge (where relevant) including the source of the knowledge, ${ }^{39}$ as well as the benefits or agreed commitments provided in return for the use of the indigenous people's knowledge. ${ }^{40}$

In contrast, the Queensland government has implemented a regime governing access to biological resources without any specific reference to traditional knowledge. The Biodiscovery Act 2004 (Qld) ('Biodiscovery Act') establishes an access and benefit-sharing regime for the purpose of facilitating access by entities to native biological resources for biodiscovery. ${ }^{41}$ While the importance of biological diversity is recognised, ${ }^{42}$ the Biodiscovery Act also has the objective of ensuring that the benefits of biodiscovery return to the State of Queensland, in the form of benefit sharing and the development of industry based on 'value added biodiscovery' ${ }^{43}$ Access to biological resources on State land ${ }^{44}$ and in Queensland waters for the purpose of biodiscovery, is subject to a 'collection authority' 45 and benefit sharing agreement. ${ }^{46}$ The operation of the Biodiscovery Act is supplemented by the Queensland Biotechnology Code of Ethics that regulates access to biological resources by 'Queensland biotechnology organisations' with specific provisions relating to traditional knowledge. ${ }^{47}$ The Code of Ethics requires the negotiation of benefit sharing arrangements with Indigenous peoples or communities where traditional knowledge is accessed and used in

\footnotetext{
${ }^{35}$ Ibid s 28(2)(b)(ii).

${ }^{36}$ Ibid s 29.

37 Ibid s 11.

${ }^{38}$ Ibid s 27.

${ }^{39}$ Ibid s 29(1)(h).

${ }^{40}$ Ibid s 29(1)(i).

${ }^{41}$ Biodiscovery Act 2004 (Qld), s 3(1)(a).

${ }^{42}$ Ibid s 3(1)(d).

${ }^{43}$ Ibid s 3(1)(b)-(c).

44 'State land' is defined in the Schedule 'Dictionary' to the Biodiscovery Act 2004 (Qld) as 'all land in Queensland that is not - (a) freehold land owned by a person other than the State or an entity representing the State or owned by the State; or (b) land, including land in a freeholding lease as defined under the Land Act 1994, contracted to be granted in fee-simple by the State to a person other than the State or an entity representing the State or owned by the State; or (c) land subject o a native title determination granting rights of exclusive possession.'

${ }^{45}$ Biodiscovery Act 2004 (Qld), s 10.

${ }^{46}$ Ibid ss 17, 34.

${ }^{47}$ Queensland Biotechnology Code of Ethics (2004), s $10<$ https://publications.qld.gov.au/dataset/qldbiotechnology-ethics/resource/47bf0b73-a1ed-4677-863f-f960b667b952>.
} 
the course of biodiscovery. ${ }^{48}$ The Code only applies to Queensland biotechnology organisations, ${ }^{49}$ and while other organisations may voluntarily subscribe to the Code there are currently only 10 'Subscribing Biotechnology Organisations'. ${ }^{50}$

The State of Victoria has recently amended the Aboriginal Heritage Act 2006 to incorporate provisions for the protection of Aboriginal intangible heritage. ${ }^{51}$ 'Aboriginal intangible heritage' is defined in the Act to mean: 'any knowledge of or expression of Aboriginal tradition, other than Aboriginal cultural heritage, and includes oral traditions, performing arts, stories, rituals, festivals, social practices, craft, visual arts and environmental and ecological knowledge, but does not include anything that is widely known to the public. ${ }^{52}$

The Aboriginal Heritage Act provides for the registration of Aboriginal intangible heritage by a 'registered Aboriginal party, registered native title holder or traditional owner group entity, ${ }^{53}$ and establishes an access regime protecting registered Aboriginal intangible heritage. A party seeking access to Aboriginal intangible heritage must enter into an Aboriginal intangible heritage agreement prior to obtaining access, ${ }^{54}$ and it is an offence under the Act to knowingly or recklessly use Aboriginal intangible heritage for commercial purposes without consent. ${ }^{55}$ The Aboriginal Heritage Act does not provide protection to traditional knowledge that is not registered as Aboriginal intangible heritage and the Secretary of the Department of Premier and Cabinet (Victorian Government) must approve applications for registration. ${ }^{56}$ While the Secretary is required to engage in consultation when making a decision whether to register Aboriginal intangible heritage there is no process established to review decisions of the Secretary. ${ }^{57}$ According to the Explanatory Memorandum to the Bill, the decision of the Secretary is not intended to be subject to review by any tribunal or the courts. ${ }^{58}$ It is unclear what expertise the Secretary will have to support making such determinations and so this process has the potential to further disenfranchise Aboriginal

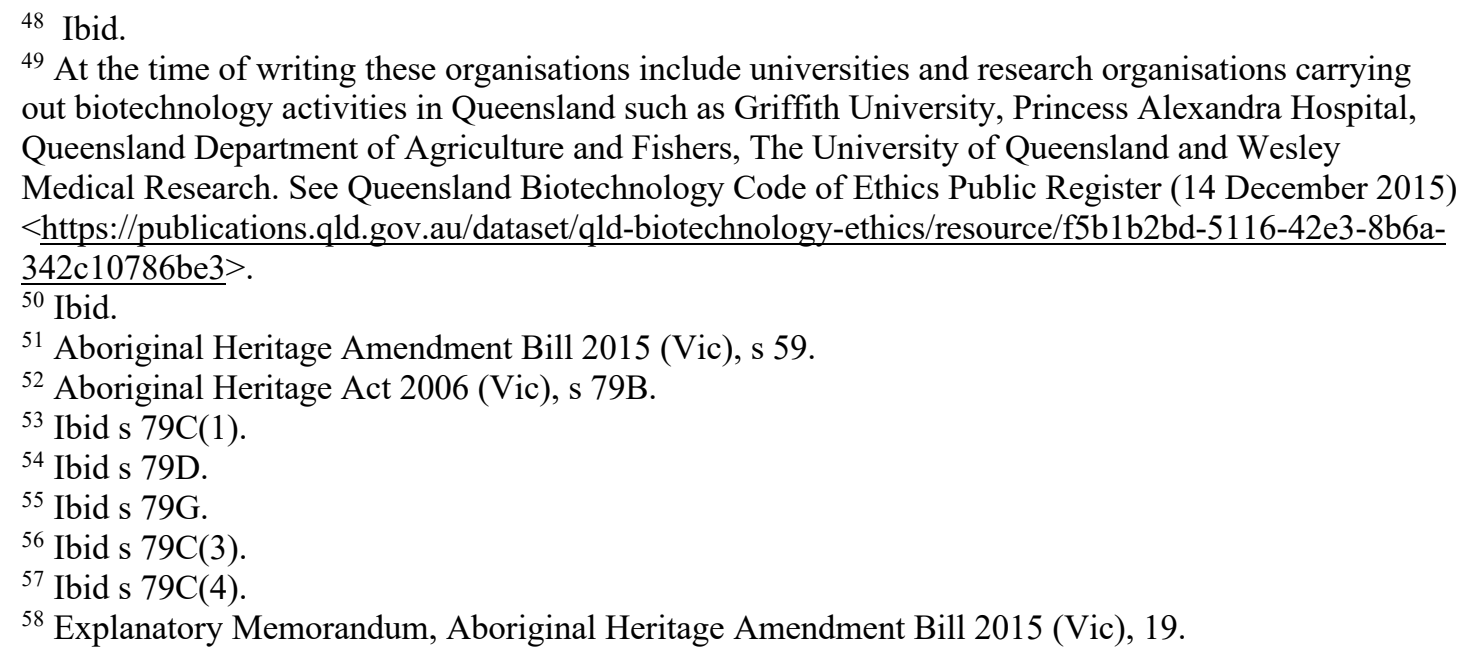
out biotechnology activities in Queensland such as Griffith University, Princess Alexandra Hospital, Queensland Department of Agriculture and Fishers, The University of Queensland and Wesley Medical Research. See Queensland Biotechnology Code of Ethics Public Register (14 December 2015) $<\underline{\text { https://publications.qld.gov.au/dataset/qld-biotechnology-ethics/resource/f5b1b2bd-5116-42e3-8b6a- }}$ $\underline{342 \mathrm{c} 10786 \mathrm{be} 3>}$.

${ }^{50}$ Ibid.

${ }^{51}$ Aboriginal Heritage Amendment Bill 2015 (Vic), s 59.

${ }^{52}$ Aboriginal Heritage Act 2006 (Vic), s 79B.

${ }^{53}$ Ibid s 79C(1).

${ }^{54}$ Ibid s 79D.

55 Ibid s 79G.

${ }^{56}$ Ibid s $79 \mathrm{C}(3)$.

${ }^{57}$ Ibid s 79C(4).

${ }^{58}$ Explanatory Memorandum, Aboriginal Heritage Amendment Bill 2015 (Vic), 19. 
communities and prevent communities from making decisions regarding the use and control of their traditional knowledge.

Due to the separation of powers between the Commonwealth, State and Territory Governments in Australia, the protection afforded to traditional knowledge is jurisdictionally limited whereby access and use is only regulated in a defined territory and, in most cases, does not cover traditional knowledge that is located on private land. As the majority of land in Australia is privately owned the terms of these regimes are easily circumvented. ${ }^{59}$ The lack of a nationally consistent regime for the protection of traditional knowledge and the resulting legal uncertainty creates an environment that fails to adequately address the misappropriation and exploitation of traditional knowledge and may discourage legitimate bio-discovery activities. $^{60}$

Despite some positive examples of collaboration between Indigenous communities and third parties ${ }^{61}$ biopiracy continues to be a problem in Australia. Not only are these acts of biopiracy deeply offensive to Indigenous people, they fail to take into account the role Indigenous people and communities play in developing and maintaining traditional knowledge. ${ }^{62}$ Critically, biopiracy can prevent indigenous people from utilising their traditional knowledge to develop and support local economies. ${ }^{63}$ Such acts represent the continuing dispossession of Indigenous and local communities who have suffered numerous wrongs, both historical and contemporary ${ }^{64}$ Rights in traditional knowledge may be used to

\footnotetext{
${ }^{59}$ AUSLIG (Australian Land Survey Information Group) 1993, Land Tenure Map, available at Geoscience Australia website

$<$ https://ecat.ga.gov.au/geonetwork/srv/eng/catalog.search?node=srv\#/metadata/a05f7892-b790-7506e044-00144fdd4fa6 $>$ also cited at note 81 in Natalie P Stoianoff, 'The Recognition of Traditional Knowledge under Australian Biodiscovery Regimes: Why Bother with Intellectual Property Rights' in Christoph Antons (ed), Traditional Knowledge, Traditional Cultural Expressions and Intellectual Property Law in the Asia-Pacific Region (Kluwer Law International 2009) 293, 307.

${ }^{60}$ Prime Minister's Science, Engineering and Innovation Council, Biodiscovery (2 December 2005) 22.

${ }^{61}$ See for example, the collaborative research project between Jarlmadangah Burru Aboriginal Corporation and Griffith University in Virginia Marshall, Terri Janke and Anthony Watson, 'Community Economic Development in Patenting Traditional Knowledge: A Case Study of the Mudjala TK Project in the Kimberley Region of Western Australia' (2013) 8(6) ILB 17. See also, David J Claudie and others, 'Ancient but New: Developing Locally Driven Enterprises Based on Traditional Medicines in Kuuku I'yu Northern Kaanju Homelands, Cape York, Queensland, Australia' in Peter Drahos and Susy Frankel (eds), Indigenous Peoples' Innovation: Intellectual Property Pathways to Development (ANU E Press 2012) 29-55.

${ }^{62}$ Robinson, Confronting Biopiracy (n 14) 101-16.

${ }^{63}$ Fourmile-Marrie (n 15) 164; Katie O'Bryan, 'The Appropriation of Indigenous Ecological Knowledge: Recent Australian Developments' (2004) 1 Macquarie Journal of International and Comparative Environmental Law 29, 32; Vandana Shiva, Biopiracy: The Plunder of Nature and Knowledge (South End Press 1997) 14.

${ }^{64}$ Fourmile-Marrie (n 15) 164; O'Bryan (n 63); Shiva (n 63). In Australia, these wrongs have been perpetrated through policies of protection, assimilation, removal and intervention. See for example, Aborigines Protection Act 1909 (NSW), Child Welfare Act 1939 (NSW) and (The Policy of Assimilation: Decisions of Commonwealth and State Ministers at the Native Welfare Conference, Canberra, 26 and 27 January 1961) $<$ http://aiatsis.gov.au/sites/default/files/catalogue resources/18801.pdf $>$.
} 
support Indigenous and local communities in creating institutions that affirm spiritual and cultural values. ${ }^{65}$

II. Sui Generis regimes for the protection of Traditional Knowledge: The examples of Peru and India

There is value in studying the solutions implemented in other jurisdictions for the purpose of informing the development and implementation of a nationally consistent regime for the protection of traditional knowledge in Australia ${ }^{66}$ Two examples of regimes for the protection of traditional knowledge are those of India ${ }^{67}$ and Peru: ${ }^{68}$ both of which draw on a range of legal tools including access and benefit sharing schemes and defensive protection through the use of databases or registers. Both India and Peru are classified as mega-diverse countries; have identified Indigenous populations; and have taken steps to protect traditional knowledge introducing in 2002 the Biological Diversity Act ('BDA') and Law No. 27811 Introducing a Protection Regime for the Collective Knowledge of Indigenous Peoples derived from Biological Resources ('Law 27811') respectively. Australia is also a megadiverse country with a legacy of invasion and colonialism that has impacted, and continues to impact, on Aboriginal and Torres Strait Islander people.

While there are similarities between the jurisdictions under consideration, there are also significant differences, from a legal, economic and cultural perspective with varying levels of recognition afforded to Indigenous or local people by their respective governments. These geographical, sociological, economic, cultural and political factors must be taken into account when considering the outcomes of the comparative analysis. ${ }^{69}$ While there are inherent dangers and limitations associated with any comparative study, these dangers do not prevent the identification of meaningful outcomes. ${ }^{70}$ The literature supports the value of considering foreign jurisdictions as a source of legal transplants, even where there are 'great material and cultural differences between the donor and recipient societies'. ${ }^{71}$

\footnotetext{
${ }^{65}$ Douglas Sanderson, 'Redressing the Right Wrong: The Argument from Corrective Justice' (2012) 62 UTLJ 93, 93.

${ }^{66}$ Stoianoff, 'Navigating the Landscape' (n 9).

${ }^{67}$ Biological Diversity Act 2002 (India) (hereafter 'BDA').

${ }^{68}$ Law No 27,811 of 2002 Introducing a Protection Regime for the Collective Knowledge of Indigenous People Derived from Biological Resources (Peru).

${ }^{69}$ Otto Kahn-Freund, 'On Uses and Misuses of Comparative Law' (1974) 37(1) The Modern Law Review 1; Watson (n 9).

${ }^{70}$ Watson (n 9) 10.

${ }^{71}$ George Mousourakis, 'Transplanting Legal Models across Culturally Diverse Societies: A Comparative Law Perspective' (2010) 57 Osaka University Law Review 87, 98; Watson (n 9) 96; Eberle (n 9) 465.
} 
The next part of this chapter will critically analyse the access and benefit sharing frameworks and databases established by India and Peru with the objective of identifying key lessons for Australia in the design and implementation of a nationally consistent regime for the protection of traditional knowledge.

\section{A. Access and benefit sharing}

India and Peru have established access and benefit sharing regimes regulating access to and use of traditional knowledge and the sharing of benefits arising out of such use, however, both countries have taken very different approaches to the design and implementation of their respective schemes. The BDA (India) establishes a centralised, bureaucratic regime regulating access to biological resources and associated knowledge with differing processes and approvals required depending on the type of user and the intended use. By contrast, Law 27811 (Peru) establishes a more streamlined regime specifically targeted at traditional knowledge regulating access to collective knowledge related to biological resources with responsibility for decision making devolved to the representative organisations of Indigenous communities.

i. $\quad$ Biological Diversity Act 2002 (India)

The BDA establishes a tiered approach with the legislation requiring parties to seek approval from centralised authorities with differing requirements and procedures applied depending on the class of user and the proposed use of Indian biological resources and associated knowledge. Approval is required from the National Biodiversity Authority prior to accessing biological resources or any associated knowledge for research or commercial utilisation or bio-survey and bio-utilisation. ${ }^{72}$ However, this requirement to obtain approval from the National Biodiversity Authority is limited to non-citizens of India; citizens of India who are non-resident for tax purposes; companies that are not incorporated or registered in India; or companies that are incorporated or registered in India that have any non-Indian participation in their share capital or management ('foreign and NRI users'). ${ }^{73}$ While the National Biodiversity Authority is required to consult with concerned local bodies in making decisions on access and benefit sharing, the ultimate decision maker in these cases is the National Biodiversity Authority with no obligation to take the needs and expectations of local bodies into account.

\footnotetext{
${ }^{72}$ BDA (n 67) s 3(1).

${ }^{73}$ Ibid s 3(2).
} 
According to the National Biodiversity Authority, over 436 applications have been received for access to biological resources and associated knowledge with 162 approvals granted since $2003 .^{74}$ This data may not represent the actual extent of access to and use of biological resources and associated knowledge by foreign and NRI users. Given the size of India and the associated biodiversity it is difficult to believe that the number of foreign and NRI users accessing biological resources and associated knowledge is limited to the reported number of approvals. This suggests either a lack of awareness of the scheme, which may be the case in early years following the entry into force of the BDA, or non-compliance.

Bavikatte and Tvedt have observed that unregulated bioprospecting continues 'through supply chains that are indifferent to regulatory requirements. ${ }^{75}$

In addition to determining whether to grant access, the National Biodiversity Authority is required to ensure that the terms and conditions of any approval result in the equitable sharing of benefits arising out of the use of the biological resources (including their by-products, innovations and practices associated with their use and related applications and knowledge).${ }^{76}$ Such benefit sharing arrangements must be on mutually agreed terms between the user party, the relevant local bodies and benefit claimers. ${ }^{77}$ The BDA provides for both monetary and non-monetary benefits including joint ownership of intellectual property rights, technology transfer and capacity building measures. ${ }^{78}$

Benefit sharing is highly regulated with the benefits determined through a meeting of the Expert Committee on ABS without consultation with the relevant local community.

Decisions are made within a short timeframe and are calculated in accordance with a 'standardized thumb-rule' as set out in the Guidelines on Access to Biological Resources and Associated Knowledge and Benefits Sharing Regulations 2014 (ABS Guidelines). ${ }^{79}$ The ABS Guidelines provide for a set schedule of benefits with little negotiation between the National Biodiversity Authority, the applicant or the local bodies. ${ }^{80}$ While the use of set percentages provides a measure of certainty for stakeholders the application of the 'thumbrule approach' conflicts with the explicit requirement in the BDA that access and benefit sharing is to be on mutually agreed terms and the process excludes local bodies from the decision making

\footnotetext{
${ }^{74}$ As at August 2018. National Biodiversity Authority, 'Total Applications Received' $<$ http://nbaindia.org/text/24/TOTALAPPLICATIONSRECEIVED.html $>$; National Biodiversity Authority, 'Approval granted to applicants' $<$ http://nbaindia.org/content/683/61/1/approvals.html $>$.

${ }^{75}$ Kabir Sanjay Bavikatte and Morten Walloe Tvedt, 'Beyond the Thumbrule Approach: Regulatory Innovations for Bioprospecting in India' (2015) 11(1) Law, Environment and Development Journal 6. ${ }^{76}$ BDA (n 67) s 21(1).

${ }^{77}$ Ibid. Benefit claimers are defined in section 2(a) as 'the conservers of biological resources, their byproducts, creators and holders of knowledge and information relating to the use of such biological resources, innovations and practices associated with such use and application.'

${ }^{78}$ Ibid s 21(2).

${ }^{79}$ Guidelines on Access to Biological Resources and Associated Knowledge and Benefits Sharing Regulations 2014.

${ }^{80}$ Bavikatte and Tvedt (n 75) 14.
} 
process. ${ }^{81}$ According to a recent publication, the National Biodiversity Authority has received $4,339,698$ rupees in royalties arising out of benefit sharing with approximately $90 \%$ of this figure coming from one arrangement. ${ }^{82}$ While the sharing of benefits is a key objective of the $\mathrm{BDA}$, it is apparent that the benefit sharing provisions are secondary to those provisions governing access. The Guidelines setting out the benefit sharing framework were not implemented until 12 years after the BDA came into force and the amount of monetary benefits received to date is very low when calculated on a per approval basis. These factors have led Kohli and Bhutani to observe that BDA is more an access regime without any benefit sharing. ${ }^{83}$

Indian citizens and companies registered in India are not entirely exempt from the approval requirements established under the BDA. Access to biological resources for 'commercial utilization, or bio-survey and bio-utilization for commercial utilization' by Indian citizens or Indian companies may only occur after giving 'prior intimation' to the State Biodiversity Board. ${ }^{84}$ The process for making an application to the State Biodiversity Board is set out in the State Biodiversity Rules to be established by each State Biodiversity Board and State Government. 26 out of 29 States have established State Biodiversity Rules and analysis of each of the Rules indicates that while the Rules are based on a standard template, there is an inconsistent approach as to the power of the State Biodiversity Board, the process for obtaining approval and the circumstances in which approval is required. For example, some States have expanded on the requirement to obtain approval for access to biological resources and associated knowledge, requiring any person seeking access to make an application not just resident Indian citizens and Indian companies. ${ }^{85}$ Furthermore, some States require approvals to be obtained for any use of biological resources and associated knowledge instead of just for commercial utilisation. ${ }^{86}$ These approaches are outside the role for the State Biodiversity Boards as established under the BDA and are in conflict with the provisions of the ABS Guidelines. ${ }^{87}$ The conflicting provisions and lack of consistency across the states creates

\footnotetext{
${ }^{81}$ BDA (n 67) s 21. See also Bavikatte and Tvedt (n 75) 14.

${ }^{82}$ The ABS Capacity Development Initiative, National Study on ABS Implementation in India (Commissioned by the ABS Capacity Development Initiative in collaboration with the Government of India, carried out by Research and Information System for Developing Countries, India Habitat Centre, New Delhi, April 2014) 22-23.

${ }^{83}$ Kanchi Kohli and Shalini Bhutani, Chasing Benefits: Issues on Access to Genetic Resources and Traditional Knowledge with reference to India's Biodiversity Regime. A post-Nagoya Protocol view on Access and Benefit Sharing (Kalpavriksh) 11.

${ }^{84}$ BDA (n 67) ss 7, 20.

${ }^{85}$ These states include Andhra Pradesh; Arunachal Pradesh; Gujarat; Karnataka; Madhya Pradesh; Maharashtra; Manipur; Meghalaya; Mizoram; Nagaland; Sikkim, Telangana; and Uttar Pradesh.

${ }^{86}$ These states include Andhra Pradesh; Arunachal Pradesh; Gujarat; Karnataka; Madhya Pradesh; Maharashtra; Manipur; Meghalaya; Mizoram; Nagaland; Sikkim, Telangana; Tripura; and Uttar Pradesh.

${ }^{87}$ BDA (n 67) ss 7, 20; ABS Guidelines (n 79) s 17(1).
} 
uncertainty for stakeholders including users, knowledge holders and authorities. This imposes a substantial burden on potential users of biological resources and associated knowledge to determine which process applies and may result in non-compliance or forum shopping. It should be noted, however, that the provisions relating to giving prior intimation to the State Biodiversity Board do not apply to 'the local people and communities of the area, including growers and cultivators of biodiversity, and vaids and hakims, who have been practicing indigenous medicine. ${ }^{88}$

The third tier under the BDA is the Biodiversity Management Committee. Each local body is required to establish a Biodiversity Management Committee within its area for the purpose of promoting conservation, sustainable use and documentation of biological diversity ${ }^{89}$ with the primary responsibility being the preparation of Peoples' Biodiversity Registers. ${ }^{90}$ According to the National Biodiversity Authority, 74,063 Biodiversity Management Committees have been established in 26 states with 23,743 established in Madhya Pradesh alone. ${ }^{91}$ Any Biodiversity Management Committee may also advise on matters that are referred to it by the State Biodiversity Board or National Biodiversity Authority and these bodies are required to consult with the relevant Biodiversity Management Committee where a decision relates to biological resources and associated knowledge within their territory. ${ }^{92}$ The Biodiversity Management Committee may also charge and collect fees from any person 'accessing or collecting any biological resources for commercial purposes from areas falling within its territorial jurisdiction. ${ }^{93}$

In addition, to the above, the approval of the National Biodiversity Authority is also required before applying for intellectual property rights over 'any invention based on any research or information on a biological resource obtained from India ${ }^{94}$ or to transfer research results to foreign and NRI users. ${ }^{95}$ Concurrent with the development of the BDA, the Indian government passed amendments to the Patents Act 1970 (India) implementing specific provisions dealing with traditional knowledge. The Patents Act $1970^{96}$ specifically excludes from patentability 'an invention which in effect, is traditional knowledge or which is an aggregation or duplication of known properties of traditionally known component or

\footnotetext{
${ }^{88}$ BDA (n 67) s 7.

${ }^{89}$ Ibid s 41(1). 'Local body' is defined in section 2(h) of the BDA as 'Panchayats and Municipalities, by whatever name called, within the meaning of clause (1) of article 243B and clause (1) of article 243Q of the Constitution and in the absence of any Panchayats or Municipalities, institutions of selfgovernment constituted under any other provision of the Constitution or any Central Act or State Act.' ${ }^{90}$ Biological Diversity Rules 2004 (India), r 22(6).

${ }^{91}$ As at March 2018. 'Biodiversity Management Committees' (National Biodiversity Authority)

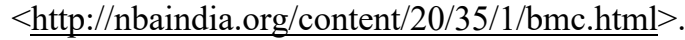

92 BDA (n 67) s 41(2); Biological Diversity Rules (n 90) r 22(7).

${ }^{93}$ BDA (n 67) s 41(3).

${ }^{94}$ Ibid s 6.

${ }^{95}$ Ibid ss 4, 19(2).

${ }^{96}$ As amended by the Patents (Amendment) Act 2002 (India).
} 
components. ${ }^{97}$ Patent applicants are required to disclose the source or geographical origin of any biological material used in an invention. Where this is not disclosed at all or properly in the complete specification there are grounds for opposition or revocation of a patent. ${ }^{98}$ Opposition or revocation is also possible where the invention is 'anticipated having regard to the knowledge, oral or otherwise, available within any local or indigenous community in India or elsewhere. ${ }^{99}$

iii. Law No. 27811 Introducing a Protection Regime for the Collective Knowledge of Indigenous Peoples Derived from Biological Resources (Peru)

Law 27811 establishes an access and benefit-sharing regime requiring that use of collective knowledge associated with biological resources is subject to the prior informed consent of the relevant Indigenous people or community. ${ }^{100}$ In contrast to the bureaucratic regime implemented in India under the BDA, Law 27811 vests responsibility for decision making in the representative organisation of the Indigenous community possessing the collective knowledge. A party seeking access to traditional knowledge for scientific, commercial or industrial purposes must apply for consent from the relevant representative organisation. ${ }^{101}$ It is then the responsibility of the representative organisation to inform the largest possible number of Indigenous people who possess the collective knowledge that they are entering into negotiations for access and benefit sharing and take into account their interests and concerns when making a decision to grant or deny access. ${ }^{102}$ There is the potential for conflict in this process particularly where collective knowledge is held by two or more Indigenous communities or where communities are represented by more than one representative organisation. Conflict between Indigenous peoples, including in relation to the obligation to consult with other Indigenous peoples and decisions regarding access and benefit sharing, shall be resolved via dispute resolution with reference to customary law and protocols, including the ability to refer the dispute to an Indigenous organisation for mediation. ${ }^{103}$ As observed by Ruiz, to reduce the likelihood for conflict it is critical that representative

\footnotetext{
${ }^{97}$ Patents Act 1970 (India), s 3(p).

98 Ibid ss 25(1)(j), 25(2)(j), 64(1)(p).

${ }^{99}$ Ibid ss 25(1)(k), 25(2)(k), 64(1)(q).

${ }^{100}$ Law No 27,811 (n 68) arts 5(d), 6.

${ }^{101}$ Ibid art 6 . In accordance with the provisions in art 14, Indigenous peoples shall be represented by their respective representative organisations with due regard being given to the traditional forms of organisation of Indigenous peoples.

102 Ibid art 6.

${ }^{103}$ Ibid art 46.
} 
organisations uphold customary laws and practices in making a decision to grant or refuse access. ${ }^{104}$

Unlike the BDA, Law 27811 does not distinguish between the types of use or user where access is for commercial or industrial purposes, the parties must enter into a benefit sharing agreement with a percentage of the benefits required to be deposited with the Fund for the Development of Indigenous Peoples. ${ }^{105}$ These 'licence contracts' for access and benefit sharing must be in writing, in the relevant native language and in Spanish, ${ }^{106}$ and must contain certain minimum provisions including a commitment of the user party to "contribute to the ability of the indigenous peoples to make use of the collective knowledge relating to its biological resources. ${ }^{107}$ The licence contract must be registered with the National Institute for the Defence of Free Competition and the Protection of Intellectual Property (INDECOPI) ${ }^{108}$ and a copy must also be provided to INDECOPI with any application for patent protection of an invention 'produced or developed on the basis of collective knowledge'. ${ }^{109}$ Details of the license contracts are not made publicly available and a recent report suggests that no licence contracts have been entered into to date under Law $27811 .{ }^{110}$

Collective knowledge that has entered into the 'public domain' is excluded from the ordinary access and benefit sharing provisions of Law $27811 .{ }^{111}$ Knowledge will be considered to have entered the public domain where it has been 'made accessible to persons other than the indigenous peoples by mass communication media such as publication or, where it has become extensively known outside the confines of the indigenous peoples and communities. ${ }^{112}$ Where the collective knowledge has entered into the public domain within the last twenty years, a percentage of the value before tax of the gross sales of goods developed on the basis of the knowledge is required to be deposited with the Fund for the Development of Indigenous Peoples. ${ }^{113}$ Indigenous people do not have the right to object to the use of collective knowledge in the public domain. They may, however, be able to claim compensation from the fund. ${ }^{114}$ This approach is intended to reflect that it is often difficult to

\footnotetext{
${ }^{104}$ Manuel Ruiz, Isabel Lapena and Susanna E Clark, 'The Protection of Traditional Knowledge in Peru: A Comparative Perspective' (2004) 3(3) Wash U Global Stud L Rev 755, 793-94.

${ }^{105}$ Law No 27,811 (n 68) arts 7-8. The Fund for the Development of Indigenous Peoples is established under art 37 of Law No 27,811.

${ }^{106}$ Ibid art 26.

${ }^{107}$ Ibid art 27.

${ }^{108}$ Ibid art 25.

${ }^{109}$ Ibid Second Complementary Provision.

${ }^{110}$ Union for Ethical BioTrade (UEBT), ABS in Peru (18 April 2016), 5

$<$ https://static1.squarespace.com/static/58bfcaf22994ca36885f063e/t/5b16992b352f539abbd558a5/152 8207661061/UEBT-ABS-Peru-2016.pdf $>$.

${ }_{111}$ Law No 27,811 (n 68) art 13.

112 Ibid.

${ }^{113}$ Ibid.

${ }^{114}$ Ruiz, Lapena and Clark (n 104) 779.
} 
identify the knowledge holders where collective knowledge has moved into the public domain. ${ }^{115}$ In contrast to the operation of conventional intellectual property law regimes, the provisions of Law 27811 attempts to capture some benefits for Indigenous and local communities over and above what would ordinarily be available to inventors should their invention move into the public domain. However, the provision has been criticised because of its failure to fully recognise the rights of Indigenous people in their collective knowledge regardless of whether the knowledge in question is secret or in the public domain. ${ }^{116}$

iv. Lessons for Australia on access and benefit sharing

There are a number of lessons for Australia arising out of the experience of India and Peru in implementing access and benefit sharing regimes. First, any regime for the protection of traditional knowledge must be based on local decision-making protocols with access regulated regardless of the proposed use or user. Drawing on the experience of India and the uncertainty created by the differing approaches of the State Biodiversity Boards in implementing their obligations, any framework adopted for the protection of traditional knowledge must be implemented consistently. This includes consistent application of provisions relating to prior informed consent for access to traditional knowledge regardless of the type of intended use or the type of user involved. Access to traditional knowledge, for any purpose, should only occur with the prior informed consent of the Aboriginal or Torres Strait Islander community and be subject to mutually agreed terms. Where access is for commercial or industrial purposes, such mutually agreed terms must include equitable benefit sharing. A nationally consistent regime will provide certainty for Aboriginal and Torres Strait Islander communities and other stakeholders and reduce the compliance burden on those parties seeking to access traditional knowledge thereby facilitating compliance and preventing forum shopping.

Requiring consistent implementation of the principles established under a national framework does not mean that there cannot be flexibility for Indigenous communities in making decisions with regards to traditional knowledge. Unlike under the BDA in India, decisions regarding access and benefit sharing must ultimately be made by the Indigenous community based on the principles of prior informed consent and mutually agreed terms and with regard to customary law and practices. Similar to the approach taken in Peru under Law 27811 , consideration should be given to the role that representative organisations may play in

\footnotetext{
${ }^{115}$ Ibid; Begona Venero Aguirre, 'The Peruvian Law on Protection of Collective Knowledge of Indigenous Peoples Related to Biological Resources' in Christophe Bellman and others (eds), Trading in Knowledge: Development Perspectives on TRIPS, Trade and Sustainability (Earthscan 2003) 285, 289.

${ }^{116}$ Ruiz, Lapena and Clark (n 104) 779.
} 
facilitating and coordinating requests for access and providing a buffer between a party seeking access and the Indigenous community and knowledge holders. Accordingly, the lesson for Australia is to develop legal framework for the protection of traditional knowledge that is nationally consistent yet flexible enough to recognise the needs and expectations of Aboriginal and Torres Strait Islander communities across Australia. This may be achieved by structuring the framework to provide for local level decision making and the recognition of customary laws and protocols. ${ }^{117}$

The second key lesson arising out of the experience of India and Peru is the importance of benefit sharing. While India and Peru promote both monetary and nonmonetary forms of benefit sharing, both countries can be criticised for failing to capture benefits for Indigenous and local communities. Benefits should form a critical component of any access agreement with regards to Aboriginal and Torres Strait Islander traditional knowledge, regardless of whether the access is for research or commercial purposes (or both). Furthermore, the quantum and type of benefit sharing must be mutually agreed and negotiated on a case by case basis having regard to the needs and expectations of the relevant Aboriginal or Torres Strait Islander community. While guidelines are useful to provide an indicative framework within which to operate, the strict application of percentages or pre-determined benefit sharing models without reference to the needs and expectations of both parties, such as seen in India and to an extent in Peru, is contrary to the principles established under the United Nations Declaration on the Rights of Indigenous People as it prevents Indigenous people from making decisions regarding their knowledge and the needs of their community. ${ }^{118}$ Indigenous communities must be able to make a determination as to the nature and quantum of benefits including any non-monetary benefits. Furthermore, access and benefit sharing arrangements must be monitored to ensure that benefits, including nonmonetary benefits, flow to the relevant Aboriginal or Torres Strait Islander community especially where such benefits are directed through a central authority or representative organisation.

B. Databases

Databases have been used in both India and Peru, at a national and local level, both to preserve and protect traditional knowledge. Databases may be used for a number of purposes

\footnotetext{
117 The recognition of customary law within the Australian legal system is supported by the Australian Law Reform Commission and already occurs at Commonwealth, state and territory levels in various fields. See Australian Law Reform Commission, Recognition of Aboriginal Customary Laws, (1986) Report No 31 [76]-[83], [194].

${ }^{118}$ UNGA, United Nations Declaration on the Rights of Indigenous Peoples (adopted 13 September 2007, entered into force 2 October 2007) UN Doc A/RES/61/295, arts 18, 31.
} 
including the preservation of traditional knowledge; the recording of legal rights over certain knowledge; or to provide evidence of prior art for the purpose of invalidating the erroneous grant of patents over traditional knowledge.

i. India: Traditional Knowledge Digital Library and People's Biodiversity Registers

In India, the Traditional Knowledge Digital Library (TKDL) was established in 2001 with the objective of preventing patents being granted over inventions based on traditional knowledge. ${ }^{119}$ The database now contains approximately 290,000 medicinal formulations based on traditional knowledge ${ }^{120}$ and includes the details of the names of medicinal formulations, the source or origin of the knowledge, method of preparation and use and details of supporting documentation. ${ }^{121}$ The knowledge contained in the database is classified according to the Traditional Knowledge Resource Classification (TKRC), which is based on the International Patent Classification system, and use of this classification system facilitates patent examiners searching the TKDL for the purpose of identifying relevant prior art that may invalidate patents over traditional knowledge. ${ }^{122}$ A representative selection of database entries are made available to the public via the TKDL website and the full database is only available to other national patent offices under a TKDL Access Agreement. As at June 2015, Access Agreements have been entered into with the United States Patent and Trademark Office, the European Patent Office, the Japan Patent Office, IP Australia, Canadian Intellectual Property Office, German Patent Office, United Kingdom Intellectual Property Office, Chile Patent Office, and the Indian Controller General of Patents, Designs and Trademarks. ${ }^{123}$

The TKDL publishes data on the outcomes in potential cases of biopiracy with 227 cases where a patent application has been withdrawn, cancelled, declared dead or terminated; amended by the applicant; or refused by the examiner on the grounds of prior art documented in the TKDL with the majority of successful outcomes being in the European Patent Office. ${ }^{124}$

\footnotetext{
119 'About TKDL' $(T K D L)<$ www.tkdl.res.in/tkdl/langdefault/Common/Abouttkdl.asp?GL=Eng>. 120 Ibid.

${ }^{121}$ See for example, the representative database entries on the TKDL webpage $<$ www.tkdl.res.in/tkdl/langdefault/common/Global Search.asp?GL=Eng $>$.

122 'Traditional Knowledge Resource Classification (TKRC)' (TKDL) $<$ www.tkdl.res.in/tkdl/langdefault/Common/TKRC.asp?GL=Eng $>$.

123 'TKDL Outcomes against Bio-Piracy' (TKDL) $<$ www.tkdl.res.in/tkdl/langdefault/common/TKDLOutcome.asp?GL=Eng $>$; See also 'Major Milestones' $(T K D L)<$ www.tkdl.res.in/tkdl/langdefault/common/milestones.asp?GL=Eng $>$. 124 'Patent Examiner(s) view on TKDL references in Examination Report' (TKDL) $<$ www.tkdl.res.in/tkdl/langdefault/common/ExaminerReport.asp?homepage=sub $>$; See also 'TKDL Outcomes against bio-piracy' (n 123).
} 
According to the Director-General of the Indian Council of Scientific and Industrial Research, there has been a 44 percent decline in patent applications at the European Patent Office over Indian traditional medicine. ${ }^{125}$ The cost of establishing and maintaining the TKDL has been calculated at 16 crore rupees, ${ }^{126}$ which represents a large saving on the estimated $\$ 200$ billion that it would cost to defend each of the formulations in the TKDL via post grant opposition or revocation proceedings. ${ }^{127}$

Despite this success, the TKDL has been criticised for protecting the interests of the Indian government rather than the traditional knowledge holders. ${ }^{128}$ Despite denials to the contrary, suspicion remains that the Indian Council of Scientific and Industrial Research may access the TKDL for research purposes and thus contribute to the problem of misappropriation of traditional knowledge. ${ }^{129}$ It is also claimed that the copying of medicinal formulations carried out by the TKDL infringes the copyright in the texts used as the source of information. ${ }^{130}$ While the Council for Scientific and Industrial Research states that the formulations are from ancient texts and 'therefore, are outside the purview of Copyright provisions' the exact publication dates of the texts that have been scanned or transcribed are unclear. ${ }^{131}$

In addition to the TKDL, the BDA provides for the establishment of People's Biodiversity Registers to document 'comprehensive information on availability and knowledge of local biological resources, their medicinal or any other use or any other traditional knowledge associated with them. ${ }^{132}$ The Biodiversity Management Committee for each local area is required to prepare a People's Biodiversity Register to be completed using the format provided by the National Biodiversity Authority. The objective of collecting such

\footnotetext{
${ }^{125}$ Speech, Prof Samir K Brahmachari, Director-General, 'CSIR at International Conference on Utilization of the Traditional Knowledge Digital Library (TKDL) as a Model for the Protection of Traditional Knowledge' Published in Report on International Conference on Utilization of the Traditional Knowledge Digital Library (TKDL) as a Model for Protection of Traditional Knowledge (22nd-24th March 2011) New Delhi, India, Annex 5, 49.

${ }^{126}$ This is the cost of establishing and maintaining the TKDL and equates to approximately 2,379,173.64 USD (conversion done 1 June 2016). R Lakshmi Poorna, M Mymoon and A Hariharan 'Preservation and protection of traditional knowledge - diverse documentation initiatives across the globe' (2014) 107(8) Current Science 1240, 1241; Latha Jishnu, 'Safeguarding ancient wisdom' (Down to Earth, 15 October 2012) <www.downtoearth.org.in/coverage/safeguarding-ancient-wisdom-39209>. See also Response by Indian Council of Scientific and Industrial Research to Request for Information from Shri Prashant Reddy T $<$ https://drive.google.com/a/uts.edu.au/file/d/0Bxi2TzVXul5Za3d4cm9xUE9PNG8/view?pli=1>. ${ }^{127}$ Poorna, Mymoon and Hariharan (n 126) 1241; Jishnu (n 126).

${ }^{128}$ Peter Drahos, Intellectual Property, Indigenous People and their Knowledge (CUP 2014) 161. ${ }^{129}$ Ibid 158.

${ }^{130}$ Prashant Reddy, 'Is the TKDL a "confidential database" and is it compliant with Indian copyright law?' (Spicy IP, 29 March 2012) < https://spicyip.com/2012/03/is-tkdl-confidential-database-and-is$\underline{\text { it.html }>\text {. }}$.

${ }^{131}$ Letter from Council of Scientific and Industrial Research to Shri Prashant Reddy T, 13 March 2012 $<$ https://drive.google.com/file/d/0Bxi2TzVXul5ZZIFfVnFjYWhTOXFCdUo0SDRINFdNZw/view>.

${ }^{132}$ Biological Diversity Rules (n 90) r 22(6).
} 
information is to facilitate the conservation and sustainable use of biological resources and to provide evidence of rights in traditional knowledge associated with biological resources. ${ }^{133}$

The requirement to establish People's Biodiversity Registers has been criticised as removing traditional knowledge from the control of traditional knowledge holders and the context within which the traditional knowledge has and continues to develop. ${ }^{134}$ Furthermore, some local communities are suspicious of the databases and have withheld information on the grounds that the People's Biodiversity Registers do not have any specific legal protection and in the belief that they may be used to facilitate biopiracy. ${ }^{135}$

As at March 2018, 6096 People's Biodiversity Registers have been established from 74,063 Biodiversity Management Committees (BMC). ${ }^{136}$ According to the National Biodiversity Authority, there are 8 states that have failed to establish any People's Biodiversity Registers despite the fact that each BMC is required to do so and there are at least 645 BMC across these States. ${ }^{137}$ Given the vast nature of India and the diversity of communities involved, it is reasonable to expect that it will take a significant amount of time and resources to complete this process for each BMC. The preparation of any People's Biodiversity Register, or any other local database, should not be rushed to meet an artificial deadline. Instead, the process should move at a pace necessary to explain the objectives and anticipated outcomes to the communities involved and obtain prior informed consent to the collection and documentation of traditional knowledge.

ii. Peru: National and Local Registers of Collective Knowledge of Indigenous Peoples

The access and benefit sharing regime in Peru is supplemented through the establishment of three different types of register: The Public National Register of Collective Knowledge of Indigenous Peoples ('Public National Register'); the Confidential National Register of Collective Knowledge of Indigenous Peoples ('Confidential National Register'); and Local Registers of Collective Knowledge of Indigenous Peoples ('Local Registers'). ${ }^{138}$ The Public National Register documents collective knowledge that is in the public domain ${ }^{139}$ and the information set out in the Public National Register is sent to the main patent offices of the

133 'FAQ' (National Biodiversity Authority) <http://nbaindia.org/content/19/16/1/faq.html $>$; See also, National Biodiversity Authority, People's Biodiversity Register Guidelines (2013).

${ }^{134}$ Kanchi Kohli, Mashqura Fared and Shalini Bhutani, 6 years of the Biological Diversity Act in India (Kalpavriksh and GRAIN 2009) 41.

${ }^{135}$ Ibid 43, 55.

136 'People's Biodiversity Register' (National Biodiversity Authority) $<$ http://nbaindia.org/content/105/30/1/pbr.html $>$.

137 'People's Biodiversity Register' (n 136); 'Biodiversity Management Committees' (n 91).

${ }^{138}$ Law No 27,811 (n 68) art 16.

${ }^{139}$ Ibid art 17. 
world so that that patent examiners can consider it as prior art when assessing the novelty and inventiveness of patent applications. ${ }^{140}$ Indigenous people may apply, through their representative organisation, to INDECOPI for their collective knowledge to be included in the Public National Register and applications for registration must include a clear and full description of the collective knowledge to be registered along with evidence of the consent of the Indigenous people to the registration of their knowledge. ${ }^{141}$ As at January 2015, there are 978 entries on the Public National Register. ${ }^{142}$

In contrast to the Public National Register, the Confidential National Register contains collective knowledge that is not in the public domain and may not be accessed by third parties. ${ }^{143}$ The objective of the Confidential National Register is the preservation and safeguarding of traditional knowledge. ${ }^{144}$ Applications for registration must be made to INDECOPI and, as with applications for inclusion on the Public National Register, applications must contain a full description of the collective knowledge to be registered and the consent of the Indigenous community to the registration. ${ }^{145}$ As at April 2015, there are over 1422 entries in the Confidential National Register with the number of entries growing year on year. ${ }^{146}$ Registration on the Public National Register or Confidential National Register is not a pre-requisite for protection under the terms of Law 27811. Instead, Law 27811 establishes a declarative regime that recognises the inherent rights of Indigenous people in their collective knowledge and registration on either the Public National Register or Confidential National Register does not establish legal rights over the collective knowledge in question.

In addition to the Public National Register and Confidential National Registers, Law 27811 recognises that Indigenous communities may create Local Registers in accordance with customary laws and practice. ${ }^{147}$ Given that Indigenous communities have always had the right to establish such databases, it has been argued that the inclusion of such a provision in Law 27811 is unnecessary. ${ }^{148}$ However, this provision not only acknowledges the rights of Indigenous communities to prepare databases in accordance with customary practices, it also

\footnotetext{
${ }^{140}$ Ibid art 23.

${ }^{141}$ Ibid art 20.

${ }^{142}$ Submission by Peru to APEC Intellectual Property Rights Experts' Group Meeting, 'Traditional Knowledge: Update About Their Protection in Peru' (2015/SOM1/IPEG/031, 2015).

${ }^{143}$ Law No 27,811 (n 68) art 18.

144 Ibid art 16.

145 Ibid art 20.

${ }^{146}$ Manuel Ruiz Muller, Experiences in the Protection of Traditional Knowledge: The Case of Peru (Law 27811), (WIPO/IPTK/GE/15/PRESENTATIONS/MANUELRUIZ, 1 April 2015).

${ }^{147}$ Law No 27,811 (n 68) art 24.

${ }^{148}$ Begona Venero Aguirre, 'The Peruvian Law on Protection of Collective Knowledge of Indigenous Peoples Related to Biological Resources' in Christophe Bellman and others (eds), Trading in Knowledge: Development Perspectives on TRIPS, Trade and Sustainability (Earthscan 2003) 285, 289.
} 
requires INDECOPI to provide technical assistance upon request. ${ }^{149}$ The approach set out in Law 27811 of facilitating but not requiring the development of local registers is consistent with United Nations Declaration on the Rights of Indigenous People which affirms the rights of Indigenous people to protect their knowledge and participate in decision making processes, ${ }^{150}$ and is in contrast to the more prescriptive and bureaucratic approach in India where a People's Biodiversity Register must be created for each local community by the BMC in accordance with the directions provided by the National Biodiversity Authority.

\section{iii. Lessons for Australia on databases}

There is a role for databases in the protection of traditional knowledge in Australia operating on the principle of prior informed consent to both safeguard and preserve traditional knowledge and also prevent the erroneous grant of patents over traditional knowledge. The databases could be structured to provide tiered protection with three types of database being established similar to those established in Peru under Law 27811. A database could be established to hold traditional knowledge in the public domain with the contents being shared with the major patent offices of the world as prior art that may be referenced in assessing novelty and inventive step and thereby reducing the erroneous grant of patents over traditional knowledge. As with the TKDL, the contents of this database may be kept confidential with access subject to a signed access agreement incorporating non-disclosure provisions.

A second database could be established, similar to the Confidential National Register under Law 27811, to hold confidential traditional knowledge as submitted by an Aboriginal or Torres Strait Islander community or knowledge holder for the purpose of preserving and safeguarding such knowledge from loss. The contents of the database would be confidential with access restricted to a particular individual(s) or community. Finally, the development of local traditional knowledge databases should be supported with an obligation on the government to provide technical support and capacity building measures upon request. Unlike the People's Biodiversity Registers in India, any local traditional knowledge database must support self-determination and be held and managed by the Aboriginal or Torres Strait Islander community in accordance with customary law and protocols.

The success of any databases will be dependent on sufficient funding and capacity building activities to ensure that the databases are implemented and maintained effectively. Legal protections for the contents of traditional knowledge databases will be essential to

\footnotetext{
${ }^{149}$ Law No 27,811 (n 68) art 24.

${ }^{150}$ United Nations Declaration on the Rights of Indigenous Peoples (n 118) arts 18, 31.
} 
building the trust of Aboriginal and Torres Strait Islander communities and ensuring the effectiveness of any database. As demonstrated by the TKDL, databases may provide a costeffective measure of preventing patents being granted over traditional knowledge especially when compared to the cost and time associated with opposition or revocation proceedings post patent grant. Despite the benefits associated with documenting traditional knowledge, it is critical that any decision to record traditional knowledge, including how such information may be stored and disseminated or accessed, must be made with the prior informed consent of the relevant knowledge holder or Indigenous community. Ensuring that traditional knowledge is access and used subject only to prior informed consent will facilitate compliance with both the Nagoya Protocol as well as the United Nations Declaration on the Rights of Indigenous Peoples. ${ }^{151}$

\section{Conclusion}

As outlined above, there is limited protection of traditional knowledge in Australia. While Australia is yet to ratify the Nagoya Protocol, the federal government is engaging in public consultations to assess the operation of the intellectual property system with regards to traditional knowledge. ${ }^{152}$ Australia must, therefore, determine how best to protect traditional knowledge in Australia and in doing so, it is essential to examine how foreign jurisdictions have approached the issue and learn from their experience in developing an innovative response. ${ }^{153}$

There is evidence to suggest that the regimes in both Peru and India have made progress in addressing the misappropriation and exploitation of traditional knowledge with both countries having had success challenging patent applications or providing invalidating prior art to prevent patents being granted over traditional knowledge. ${ }^{154}$ India and Peru have taken very different approaches in developing their respective regimes and, as set out above, there are lessons for Australia arising out of their experience. These lessons arise from both the relative strengths and weaknesses of each regime and there is as much to learn from the cautionary tales as there is from any success. These lessons include the importance of local governance and decision making in access and benefit sharing regimes based on the principles of prior

\footnotetext{
${ }^{151}$ Nagoya Protocol (n 6) arts 6, 7, 12; United Nations Declaration on the Rights of Indigenous Peoples (n 118 ) arts $18,31$.

152 'Indigenous Knowledge Consultation' (IP Australia) < www.ipaustralia.gov.au/about-us/publicconsultations/indigenous-knowledge-consultation>. ${ }^{153}$ Stoianoff, 'Navigating the Landscape' (n 9); Eberle (n 9); Watson (n 9).

${ }^{154}$ Manuel Ruiz, 'Peru: Seeking benefit sharing through a defensive approach - the experience of the National Commission for the Prevention of Biopiracy' in Manuel Ruiz and Ronnie Vernooy (eds), The Custodians of Biodiversity: Sharing Access and Benefits of Genetic Resources (Earthscan 2012) 43, 47-48; 'TKDL Outcomes against bio-piracy' (n 123).
} 
informed consent and self-determination as well as the potential for both national and local traditional knowledge databases.

A framework for the protection of traditional knowledge associated with natural resource management in the state of New South Wales, Australia, was proposed in the recent White Paper 'Recognising and Protecting Aboriginal Knowledge Associated with Natural Resource Management'. ${ }^{155}$ The White Paper proposed the use of an access and benefit sharing regime in conjunction with databases and was presented to the Office of Environment and Heritage of New South Wales Government in 2014 and also submitted to IP Australia as part of its Indigenous Knowledge Consultation. ${ }^{156}$ Further research is currently being undertaken to conduct an in-depth comparative analysis of the regimes of Peru and India with an emphasis on the specific mechanisms used to effect the protection of traditional knowledge and the experience of both countries in the design and implementation of the regimes. Key themes in this analysis include scope and objectives; institutions and funding; access and benefit sharing; databases; and interaction with other laws. The outcome of the analysis will be to identify key lessons for Australia in the design and implementation of a nationally consistent regime for the protection of traditional knowledge taking into account the inherent differences between the jurisdictions studied including economic, cultural and legal factors. ${ }^{157}$

Any solution for the protection of traditional knowledge in Australia must be developed not just in consultation with but instead with the informed participation of Aboriginal and Torres Strait Islander people at every stage. The United Nations Declaration on the Rights of Indigenous Peoples sets out principles governing consultation with and the participation of Indigenous peoples in decisions or measures that affect their rights. ${ }^{158} \mathrm{~A}$ failure to engage in appropriate consultation and ensure the free participation of Indigenous peoples in decision making will result in a system that fails to meet the needs and expectations of Aboriginal and Torres Strait Islander peoples and ultimately erode trust in any regime. Each proposed mechanism must be developed in such a way as to provide for selfdetermination and allow each Aboriginal or Torres Strait Islander community to determine the terms on which access to traditional knowledge will be granted; what benefits are sought and how those benefits may be distributed; and what traditional knowledge, if any, may be included in any database. Operating within a framework of pluralism, it is suggested that an appropriate solution will ultimately incorporate different legal tools including customary law or protocols. The current research will contribute to the formulation of new approaches to the

\footnotetext{
${ }^{155}$ UTS - Indigenous Knowledge Forum and North West Local Land Services, Recognising and Protecting Aboriginal Knowledge Associated with Natural Resource Management: White Paper for Office of Environment and Heritage NSW (2014).

156 'Indigenous Knowledge Consultation' (n 152).

${ }^{157}$ Kahn-Freund (n 69); Watson (n 9).

${ }^{158}$ United Nations Declaration on the Rights of Indigenous Peoples (n 118) arts 18, 19.
} 
protection of traditional knowledge in Australia and will be directed towards identifying key lessons for Australia in the development and implementation of a nationally consistent regime for the protection of traditional knowledge with a view to using rights in traditional knowledge as a tool to return to Aboriginal and Torres Strait Islander people institutions that reaffirm indigenous values, practices and culture. ${ }^{159}$

${ }^{159}$ Sanderson (n 65). 